\title{
HUBUNGAN KARAKTERISTIK, PENGETAHUAN DAN MOTIVASI PERAWAT DENGAN KEPATUHAN CUCI TANGAN DI RUANG RAWAT INAP RSU SURYA HUSADHA DENPASAR
}

\author{
Ni Luh Putu Handayani*, I Ketut Suarjana, Rina Listyowati \\ Program Studi Kesehatan Masyarakat Fakultas Kedokteran Universitas Udayana \\ *email : putu.handayani17@gmail.com
}

\begin{abstract}
ABSTRAK
Kepatuhan mencuci tangan perawat merupakan salah satu faktor yang mempunyai pengaruh besar terhadap pencegahan terjadinya infeksi rumah sakit. Perawat memiliki andil yang sangat besar terhadap terjadinya penyebaran infeksi rumah sakit karena perawat berinteraksi langsung kepada pasien selama 24 jam. Kegagalan dalam melaksanakan cuci tangan sebelum kontak dengan pasien dan selama perawatan pasien, dapat menyebabkan terjadinya infeksi rumah sakit. Dalam penelitian ini bertujuan untuk mengetahui hubungan antara karakteristik, pengetahuan dan motivasi perawat dengan kepatuhan mencuci tangan. Penelitian ini adalah penelitian deskriptif dengan menggunakan desain cross - sectional. Responden yang digunakan sebanyak 97 responden dengan tehnik proportionated stratified random sampling. Hasil penelitian menunjukkan bahwa ada hubungan yang signifikan antara karakteristik (umur) dengan kepatuhan cuci tangan ( $\mathrm{p}=0,007, \mathrm{PR}=3,68)$, tingkat pendidikan dengan kepatuhan mencuci tangan $(\mathrm{p}=0,021, \mathrm{PR}=0,33)$, pengetahuan dengan kepatuhan cuci tangan $(\mathrm{p}=0,003, \mathrm{PR}=4,16)$ dan motivasi dengan kepatuhan cuci tangan $(\mathrm{p}=0,013)$. Untuk variabel yang tidak berhubungan dengan kepatuhan petugas mencuci tangan yaitu masa kerja dengan kepatuhan cuci tangan $(p=0,139, P R=2,04)$ dan jenis kelamin dengan kepatuhan perawat mencuci tangan $(p=0,069, P R=0,34)$. Simpulan yang diperoleh bahwa pengetahuan dan motivasi perawat di RSU Surya Husadha sangat signifikan terhadap kepatuhan perawat melakukan cuci tangan. Saran peneliti agar edukasi, bimbingan dan pengawasan kepada perawat tentang pelaksanaan cuci tangan terus ditingkatkan agar kepatuhan cuci tangan semakin baik sehingga kejadian infeksi rumah sakit dapat dicegah.
\end{abstract}

Kata kunci: Karakteristik, pengetahuan, motivasi, kepatuhan mencuci tangan.

\begin{abstract}
Nurse compliance in nurses washing their hands is one of the factors that has a major influence on the prevention of hospital infections. Nurses have a very large contribution to the spread of hospital infections because nurses interact directly with patients for 24 hours. Failure to carry out hand washing prior to contact with patients and during patient care, can cause hospital infections. In this study aims to determine the relationship between characteristics, knowledge and motivation of nurses with compliance to wash hands. This research is a descriptive study using cross-sectional design. Respondents used were 97 respondents with proportionated stratified random sampling technique. The results showed that there was a significant relationship between characteristics (age) with hand washing compliance $(\mathrm{p}=0.007, \mathrm{PR}=3.68)$, level of education with hand washing compliance $(p=0.021, P R=0.33)$, knowledge with compliance hand washing $(p=0.003, P R=4.16)$ and motivation with hand washing compliance $(p=0.013)$. For variables not related to compliance with hand washing officers, namely the length of service with compliance with washing hands $(p=0.139, P R=2.04)$ and gender with compliance with nurses washing hands $(p=0.069, P R=0.34)$. Conclusions obtained that the knowledge and motivation of nurses at Surya Husadha General Hospital are very significant to the compliance of nurses doing hand washing. Researchers suggest that education, guidance and supervision of nurses on the implementation of hand washing continue to be improved so that compliance with hand washing is better so that the incidence of hospital infections can be prevented.
\end{abstract}

Keywords: Characteristics, knowledge, motivation, hand washing compliance.

\section{PENDAHULUAN}

Rumah sakit sebagai sarana pelayanan kesehatan dapat menjadi sumber infeksi. Kejadian infeksi nosokomial di rumah sakit merupakan masalah penting di seluruh dunia dan terus menerus meningkat 
dalam setiap tahunnya.Tingkat infeksi nosokomial berkisar dari yang terendah $1 \%$ diberapa negara di Eropa dan Amerika sampai lebih dari 40\% di Asia, Amerika latin dan Afrika sub-sahara (Lynch et.all, 1997). Sedangkan kejadian infeksi nosokomial yang terjadi di Indonesia berdasarkan dari hasil penelitian yang dilakukan di 11 RS di DKI Jakarta pada tahun 2004 menunjukkan bahwa 9,8\% pasien rawat inap mendapatkan infeksi nosokomial selama dirawat di rumah sakit. Faktor-faktor penunjang peningkatan kejadian infeksi nosokomial ini karena meningkatnya pasien yang lemah yang masuk ke RS dan menggunakan tehnologi invasif berisiko tinggi (Schaffer,2005).

Saat ini angka kejadian infeksi nosokomial telah dijadikan tolak ukur dalam mutu pelayanan di Rumah Sakit. Izin operasional Rumah Sakit dapat dicabut jika kejadian infeksi nosokomial di rumah sakit tersebut tinggi, bahkan pihak asuransipun tidak akan mengklaim biaya pasien jika ternyata pasien mendapatkan infeksi nosokomial. Untuk itu sesuai dengan surat edaran direktur jenderal bina pelayanan medik nomor HK.03.01/III/3744/08 diwajibkan bagi seluruh pelayanan kesehatan agar melaksanakan program pencegahan dan pengendalian infeksi dengan membentukan komite dan tim PPI di rumah sakit.

Mencuci tangan merupakan pilar utama dalam pelaksanaan mencegah dan mengendalikan infeksi. Proses membuang kotoran dan debu secara mekanis dari kulit kedua belah tangan dengan memakai sabun atau air mengalir serta dengan menggunakan handrub yang bertujuan untuk menekan dan menghambat pertumbuhan kuman pada tangan dapat dilakukan dengan mencuci tangan. (Linda, 2004).

Kegagalan dalam membersihkan tangan dan kesehatan tangan yang tepat, dianggap sebagai sebab utama terjadinya infeksi nosokomial (Boyce dan Pittet, 2001).Banyak faktor yang berhubungan dengan prilaku yang berhubungan dengan cuci tangan dikalangan perawat. Menurut Tohamik (2003) bahwa faktor-faktor yang mempengaruhi kepatuhan perawat dalam melaksanakan kebersihan tangan terhadap pencegahan infeksi rumah sakit adalah faktor internal meliputi karakteristik individu (jenis kelamin, umur, jenis pekerjaan, masa kerja, tingkat pendidikan), faktor psikososial (sikap terhadap pnyakit, ketegangan kerja, rasa takut dan persepsi terhadap risiko), faktor pengetahuan, faktor motivas dan kesadaran. Faktor eksternal meliputi faktor organisasi manajemen, faktor fasilitas, faktor tempat tugas, dan faktor bahan cuci tangan terhadap kulit.

RSU Surya Husadha Denpasar merupakan salah satu RS swasta sudah menjalankan pelaksanaan program PPI dengan membentuk komite PPI yang diketuai oleh seorang dokter spesialis interna dimana pelaksanaan program PPI yang dijalankan menitik beratkan pada peningkatan kebudayaan petugas dalam melakukan kebersihan tangan/mencuci tangan. Sesuai hasil surveilans dan observasi peneliti bersama Tim PPI di RSU Surya Husadha Denpasar pada bulan Januari sampai dengan Desember tahun 2016 angka infeksi luka operasi sebesar 0,45\% angka kejadian tersebut melebihi dari target atau standar yang ditetapkan yaitu sebesar 0,20\%. Kejadian infeksi ini kemungkinan juga disebabkan oleh masih 
rendahnya kepatuhan perawat dalam melakukan kebersihan tangan berdasarkan five moment hand hygiene yaitu mencuci tangan sebelum kontak dengan pasien sebesar $64,9 \%$, dari target yang diharapkan oleh rumah sakit sebesar $\geq 90 \%$.Upaya yang juga telah dilakukan oleh pihak manajemen rumah sakit untuk membantu pelaksanaan program pencegahan dan pengendalian infeksi tersebut adalah dengan membuat prosedur mencuci tangan dan menyediakan fasilitas cuci tangan baik berupa wastafel atau handrub serta poster cuci tangan di seluruh area rumah sakit dan menunjuk satu orang perawat yang bertanggung jawab untuk memonitoring pengendalian infeksi di setiap shift jaga di semua unit perawatan. Peningkatan pengetahuan petugas terkait kebersihan tangan dilakukan juga melalui edukasi yang di berikan oleh Komite PPI yang bekerjasama dengan bagian pendidikan dan latihan RS.

Rendahnya pelaksanaan kebersihan cuci tangan di RSU Surya Husadha terjadi karena beberapa alasan yang mendasar sehingga petugas enggan melakukan kebersihan tangan.Adapun beberapa alasan tersebut diantaranya keterbatasan waktu, merasa tangannya bersih dan persepsi kondisi pasien yang dianggap tidak menularkan penyakit. Hal - hal yang menjadi alasan perawat tersebut berkaitan erat dengan pengetahuan, sikap, persepsi dan motivasi yang merupakan sub-bagian faktor internal perawat yang sangat berpengaruh terhadap tingkat kepedulian untuk melakukan kebersihan tangan. Selain itu kepatuhan petugas dalam melaksanakan tugasnya sesuai dengan tanggung jawabnya yaitu salah satunya dengan melaksanakan prosedur mencuci tangan dipengaruhi oleh faktor motivasi.Motivasi adalah merupakan kondisi yang dapat menggerakkan seseorang secara terarah untuk mencapai tujuan kerja.

Berdasarkan fenomena tersebut diatas maka peneliti tertarik untuk melakukan penelitian tentang hubungan karakteristik, pengetahuan dan motivasi perawat dengan kepatuhan cuci tangan di ruang rawat inap RSU Surya Husadha Denpasar.

\section{METODE}

Jenis penelitian yang digunakan adalah penelitian deskriptif dengan desain cross-sectional.Tempat penelitian ini dilaksanakan di ruang rawat inap RSU Surya Husadha Denpasar, pada bulan Maret sampai dengan Juni tahun 2017. Sampel penelitian adalah perawat di RSU Surya Husadha pada tahun 2017 yang bertugas di ruang rawat inap RSU Surya Husadha terdiri dari perawat Ruang Rawat Inap Lantai 4 sebanyak 46 orang, perawat Ruang Rawat Inap Lantai 3 sebanyak 38 orang, Ruang Rawat Inap Lantai 2 sebanyak 15 orang, perawat ruang bayi sebanyak 10 orang dan perawat Ruang Perawatan Intensif sebanyak 20 orang. Sampel diambil dengan teknik tehnik probability sampling yaitu proportionated stratified random sampling. Data dikumpulkan oleh peneliti dengan instrumen kuesioner dan lembar observasi.Data yang terkumpul dianalisis secara analisis uivariat, dan bivariat.

\section{HASIL}

Gambaran larakteristik, pengetahuan, motivasi dan kepatuhan perawat 
Gambaran karakteristik perawat di Tabel 1 Karakteristik, pengetahuan, RS Surya Husada disajikan pada tabel 1 motivasi dan kepatuhan (n=97) dibawwah ini:

\begin{tabular}{|c|c|c|}
\hline Karakteristik & Frekuensi & $(\%)$ \\
\hline \multicolumn{3}{|l|}{ Umur } \\
\hline$\geq 28$ tahun & 57 & 58,8 \\
\hline$<28$ tahun & 40 & 41,2 \\
\hline \multicolumn{3}{|l|}{ Jenis kelamin } \\
\hline Laki-laki & 14 & 14,4 \\
\hline Perempuan & 83 & 85,6 \\
\hline \multicolumn{3}{|l|}{ Masa Kerja } \\
\hline$\geq 4$ tahun & 51 & 52,6 \\
\hline$<4$ tahun & 46 & 47,4 \\
\hline \multicolumn{3}{|l|}{ Tingkat Pendidikan } \\
\hline \multicolumn{3}{|l|}{ D3 Keperawatan } \\
\hline S1 keperawatan & 43 & 44,3 \\
\hline Tingkat Pengetahuan & 54 & 55,7 \\
\hline \multicolumn{3}{|l|}{ Baik } \\
\hline \multicolumn{3}{|l|}{ Kurang } \\
\hline Motivasi & 59 & 60,8 \\
\hline Tinggi & 38 & 39,2 \\
\hline \multicolumn{3}{|l|}{ Rendah } \\
\hline Kepatuhan & 63 & 64,9 \\
\hline Patuh & 34 & 35,1 \\
\hline \multicolumn{3}{|l|}{ Tidak Patuh } \\
\hline & 63 & 64,9 \\
\hline & 34 & 35,1 \\
\hline
\end{tabular}

Berdasarkan tabel 1 dapat dilihat bahwa sebagian besar perawat berusia $\geq 28$ tahun sebanyak 58 perawat $(59,8 \%)$, dari jenis kelamin perawat lebih banyak berjenis kelamin perempuan yaitu 83 perawat $(85,6 \%)$, dengan masa kerja yang sebagian besar $\geq 4$ tahun sebanyak 51 perawat $(52,6 \%)$ dan dilihat dari tingkat pendidikan yang paling banyak adalah perawat dengan tingkat pendidikan S1 keperawatan sebanyak 54 orang $(55,7 \%)$, sebagian besar memiliki tingkat pengetahuan tinggi sebanyak 59 perawat $(60,8 \%)$ dan motivasi yang tinggi sebanyak 63 perawat $(64,9 \%)$, dan patuh melakukan cuci tangan sebanyak 74 responden $(76,3 \%)$.

Gambaran Tingkat Kepatuhan Pelaksanaan Cuci Tangan Perawat Berdasarkan Karakteristik Perawat di RSU Surya Husadh 
Gambaran tingkat kepatuhan cuci tangan berdasarkan karakteristik perawat, disajikan pada tabel 2 dibawah ini:

Tabel 2 Gambaran Tingkat Kepatuhan

Pelaksanaan Cuci Tangan Perawat

Kepatuhan mencuci

\begin{tabular}{cccccc} 
Variabel bebas & \multicolumn{2}{c}{ tangan } & p-value & PR & (95\% CI) \\
\cline { 2 - 3 } & $\begin{array}{c}\text { Patuh } \\
\mathbf{f}(\%)\end{array}$ & Tidak & Patuh $\mathrm{f}(\%)$ & &
\end{tabular}

\section{Karakteristi:}

Umur

\begin{tabular}{lccccc}
$\geq 28$ tahun & $49(86)$ & $8(14)$ & 0,007 & 3.68 & $1,374-9,832$ \\
$\begin{array}{l}<\text { 28tahun } \\
\text { Jenis Kelamin }\end{array}$ & $25(62,5)$ & $15(37,5)$ & & & \\
$\quad$ Laki-laki & $8(57,1 \%)$ & $6(42,9 \%)$ & 0,069 & 0,34 & $0,105-1,123$ \\
$\quad \begin{array}{l}\text { Perempuan } \\
\text { Masa Kerja }\end{array}$ & $66(79,5 \%)$ & $17(20,5 \%)$ & & & \\
$\geq 4$ tahun & $42(82,4 \%)$ & $9(17,6 \%)$ & 0,139 & 2,04 & $0,785-5,308$ \\
$<4$ tahun & $32(69,6 \%)$ & $14(30,4 \%)$ & & & \\
$\begin{array}{l}\text { Pendidikan } \\
\text { D3 Kep }\end{array}$ & $28(65,1)$ & $15(34,9)$ & 0,021 & 0,33 & $0,122-0,863$ \\
$\quad$ S1 Kep & $46(85,2)$ & $8(14,8)$ & & & \\
Pengetahuan & & & & & \\
$\quad$ Tinggi & $51(86,4)$ & $8(13,6)$ & 0,003 & 4,16 & $1,545-11,181$ \\
$\quad$ Rendah & $23(60,5)$ & $15(39,5)$ & & & \\
Motivasi & & & & & \\
$\quad$ Tinggi & $53(84,1)$ & $10(15,9)$ & 0,013 & 3,28 & $1,248-8,629$ \\
$\quad$ Rendah & $21(61,8)$ & $13(38,2)$ & & & \\
\hline
\end{tabular}

Berdasarkan tabel 2 di atas diketahui bahwa terdapat ada empat variabel yang berhubungan kepatuhan mencuci tangan yaitu: Umur ( $\mathrm{PR}=3.68,95 \% \mathrm{CI}=1,374-9,832$, serta nilai $\mathrm{p}=0,007)$, pendidikan $(\mathrm{PR}=0,33$, $95 \% \mathrm{CI}=0,122-0,863, \quad \mathrm{p}=0,021)$, tingkat pendidikan $\quad(\mathrm{PR}=0,33$, serta nilai 95\% $\mathrm{CI}=0,122-0,863, \mathrm{p}=0,021)$, pengetahuan $(\mathrm{PR}=4,16, \quad 95 \% \mathrm{CI}=1,545-11,181, \quad \mathrm{p}=0,003$, motivasi $\quad(\mathrm{PR}=3,28, \quad 95 \% \mathrm{CI}=1,248-8,629$, $\mathrm{p}=0,013$ )

\section{DISKUSI}

\section{Hubungan Faktor Sosio Demografi} Dengan Kepatuhan Cuci Tangan

Pada penelitian ini didapatkan hubungan antara umur dengan kepatuhan cuci tangan ( $p=0,007, P R=3,68)$. Ini menunjukkan bahwa ada hubungan antara umur dengan kepatuhan cuci tangan perawat. Umur perawat yang bekerja di RSU Surya Husadha $\geq 28$ tahun memiliki tingkat kepatuhan cuci tangan yang baik $86 \%$, hal ini mencerminkan bahwa semakin 
bertambahnya usia seseorang akan mempengaruhi pola pikir yang baik dalam bekerja terutama dalam mencegah kejadian infeksi rumah sakit dengan melakukan cuci tangan yang baik dan benar. Seiring dengan bertambahnya usia perawat, pengalaman dalam bekerja dan kesadaran akan pentingnya kesehatan cuci tangan juga meningkat terutama dalam hal pengcegahan infeksi rumah sakit. Penelitian ini didukung oleh Natalina (2010) dan Hassan (2004) yang juga menunjukkan adanya hubungan antara umur dengan kepatuhan mencuci tangan.Usia mempengaruhi pola pikir seseorang dalam perilaku. Semakin cukup umur seseorang maka tingkat kematangan dan kekuatan seseorang akan lebih matang dalam berpikir dan bekerja. Sehingga semakin dewasa seorang perawat diharapkan semakin dapat meningkatkan kinerjanya dalam hal ini kepatuhan mencuci tangan guna mencegah terjadinya infeksi rumah sakit.

Sedangkan dari hasil gambaran jenis kelamin terhadap tingkat kepatuhan perawat dalam melakukan cuci tangan dengan menggunakan uji chi square didapatkan nilai $\mathrm{p}=0,069$, hal ini menunjukkan bahwa tidak ada hubungan jenis kelamin dengan kepatuhan cuci tangan. Sejalan dengan penelitian yang dilakukan oleh Setyawati (2009) yang menyatakan bahwa jenis kelamin tidak ada hubungannya dengan ketaatan mencuci tangan dengan nilai $\mathrm{p}=0.411$ dan Sumaningrum (2015) yang menyatakan bahwa jenis kelamin tidak ada hubungannya dengan kepatuhan mencuci tangan $(p=0,725)$. Dalam penelitian ini kesempatan yang diberikan kepada responden sama baik laki-laki maupun perempuan tetapi dari segi jumlah sangat tidak seimbang sehingga untuk analisa hubungan antara jenis kelamin dan kepatuhan cuci tangan perawat perlu penelitian lebih lanjut dengan sampel yang sama. Namun dilihat dari hasil kepatuhan cuci tangan antara laki-laki dan perempuan, diperoleh bahwa kepatuhan cuci tangan perawat perempuan lebih tinggi dibanding dengan laki-laki. Hal ini mencerminkan bahwa perempuan lebih menitikberatkan pada pelaksanaan tugas dengan baik dan hubungan kerjanya sehingga lebih patuh dalam melaksanakan cuci tangan dibandingkan pada laki-laki yang cenderung melanggar aturan. Selain itu antara laki-laki dan perempuan terdapat kebiasaan mengenai pola hidup bersih (Tones dan Tilfod, 2001).Hal ini juga dapat menyebabkan kepatuhan cuci tangan pada perempuan lebih tinggi dibandingkan pada laki-laki.

Dari gambaran tingkat kepatuhan pelaksanaan cuci tangan perawat berdasarkan masa kerja diperoleh hasil bahwa tidak ada hubungan masa kerja perawat dengan kepatuhan cuci tangan di RSU Surya Husadha $(p=0,139)$. Dilihat dari proporsi kepatuhan cuci tangan perawat yang memiliki masa kerja $>4$ tahun tingkat kepatuhannya lebih tinggi dibandingkan dengan perawat yang memiliki masa kerja < 4 tahun ini menunjukkan bahwa makin lama pengalaman kerja seseorang, maka semakin terampil petugas tersebut. Perawat yang sudah lama bekerja pada bidang tugasnya, makin mudah memahami tugasnya sehingga dalam hal pencegahan infeksi perawat akan lebih patuh melaksanakan cuci tangan. Namun secara statistik masa kerja dalam penelitian ini tidak ada hubungan yang bermakna terhadap kepatuhan cuci 
tangan. Hal ini kemungkinan besar terjadi pada beberapa perawat dengan masa kerja yang lama lebih dari 4 tahun merasa sebagai seorang senior yang tidak akan berani ditegur oleh yunior jika melakukan kesalahan, serta belum adanya sanksi/punishment bagi seorang perawat yang tidak patuh dalam hal mencuci tangan dari pihak rumah sakit. Penelitian ini sejalan dengan penelitian yang dilakukan oleh Nurhayati (1997) yang mengatakan bahwa tidak ada hubungan lamanya bekerja dengan kepatuhan mencuci tangan dimana nilai $\mathrm{p}=0,107$.

Dan dari hasil uji chi square yang sudah dilakukan terhadap tingkat pendidikan, diperoleh hasil bahwa ada hubungan tingkat pendidikan dengan kepatuhan cuci tangan $(\mathrm{p}=0,021 \quad \mathrm{PR}=0,33)$. Tingkat pendidikan perawat di RSU Surya Husadha sebagian besar S1 Keperawatan yang memiliki peluang untuk patuh dalam melakukan cuci tangan sebanyak 0,33 kali lebih besar dibandingkan dengan perawat yang memiliki tingkat pendidikan D3 keperawatan. Perawat dengan pendidikan S1 Keperawatan memiliki pengaruh terhadap pola pikir yang baik serta kemampuan yang tinggi dalam melaksanakan tugasnya sehingga perawat yang memiliki pendidikan yang tinggi akan lebih patuh, dalam hal ini perawat lebih patuh melakukan cuci tangan untuk mencegah infeksi nosokomial.

Penelitian ini sejalan dengan penelitian yang dilakukan oleh Natalina (2010) yang menyatakan bahwa pendidikan mempunyai hubungan dengan kepatuhan perawat mencuci tangan. Sama dengan halnya pendapat Notoadmojo (2005) bahwa pendidikan akan membuat individu menuju pada suatu perubahan perilaku yang diinginkan.

\section{Hubungan Pengetahuan Dengan \\ Kepatuhan Cuci Tangan}

Dari hasil penelitian diperoleh bahwa sebagian besar responden memiliki pengetahuan tinggi sebanyak 51 orang dengan kepatuhan cuci tangan yang patuh sebesar $86,4 \%$. Didukung oleh hasil uji chi square yang telah dilakukan dengan hasil $\mathrm{p}=0,003 \quad \mathrm{PR}=4,16$, hal ini menunjukkan bahwa ada hubungan pengetahuan dengan kepatuhan cuci tangan. Perawat yang berpengetahuan tinggi memiliki peluang untuk patuh melakukan cuci tangan sebesar 4,16 kali lebih banyak dibanding dengan perawat yang memiliki pengetahuan rendah. Dengan memiliki pengetahuan yang tinggi terutama tentang pelaksanaan cuci tangan dapat membentuk tindakan positif dan meningkatkan kesadaran perawat dalam mencegah infeksi nosokomial dengan patuh melaksanakan cuci tangan.

Hasil penelitian ini sejalan dengan penelitian Sumaningrum (2015) yang menyatakan bahwa pengetahuan mempunyai hubungan yang bermakna dengan kepatuhan dalam melaksanakan kebersihan tangan.Sesuai dengan teori Tohamik (2003) bahwa tindakan dalam hal ini kepatuhan petugas dalam melakukan cuci tangan dipengaruhi oleh berbagai faktor termasuk didalamnya adalah pengetahuan responden.Namun dari hasil kuesioner yang telah diisi perawat, terkait pengetahuan tentang macam-macam mencuci tangan serta pentingnya mencuci tangan sebelum dan setelah menggunakan alat pelindung diri masih kurang, sehingga perlu diberikan 
pelatihan untuk meningkatkan pengetahuan perawat tersebut.

\section{Hubungan Motivasi Kepatuhan Cuci Tangan}

Dari hasil penelitian yang diperoleh bahwa perawat yang memiliki motivasi tinggi sebanyak 53 orang dengan kepatuhan perawat dalam melakukan cuci tangan sebesar $84,1 \%$. Didukung dengan uji chi square yang telah dilakukan diperoleh hasil $\mathrm{p}=0,013 \mathrm{PR}=3,28$, ini berarti ada hubungan yang signifikan antara motivasi dengan kepatuhan cuci tangan. Perawat dengan motivasi tinggi memiliki peluang untuk lebih patuh dalam mencuci tangan sebesar 3,28 kali lebih besar dibanding dengan perawat dengan motivasi rendah. Hal ini menunjukkan bahwa semakin tinggi motivasi seseorang maka tingkat kepatuhannya akan semakin baik. Motivasi memiliki hubungan erat dengan perilaku.Motivasi tinggi yang dimiliki perawat yang bekerja di RSU Surya Husadha membentuk perilaku yang dilakukan secara berulang-ulang sehingga membentuk kebiasaan baik terkait kepatuhan untuk mencegah infeksi nosokomial dengan melaksanakan cuci tangan.Kepatuhan cuci tangan itu adalah salah satu contoh dari kebiasaan atau perilaku yang dilakukan secara berulang sehingga motivasi seseorang menjadi sangat penting sebagai dasar dalam pembentukan perilaku kepatuhan cuci tangan perawat.Ada beberapa hal yang perlu di perhatikan dalam motivasi perawat dari hasil kuesioner yang telah terisi bahwa masih ada perawat yang termotivasi melakukan cuci tangan hanya bila ada pengawasan dari atasan saja.Untuk itu diperlukan pendekatan dan edukasi kembali kepada perawat tentang pentingnya melaksanakan cuci tangan dengan baik dan benar untuk pencegahan terhadap kejadian infeksi nosokomial di Rumah Sakit.

Hasil penelitian ini sejalan dengan penelitian Selly (2013) berjudul "Hubungan Motivasi dengan Kepatuhan Perawat Dalam Melaksanakan Enam Langkah Lima Moment Cuci tangan di Ruang Intensif RSUP Sanglah" yang menyatakan bahwa pengetahuan mempunyai hubungan yang bermakna dengan kepatuhan dalam melaksanakan kebersihan tangan.Sesuai dengan teori Tohamik (2003) bahwa tindakan dalam hal ini kepatuhan petugas dalam melakukan cuci tangan dipengaruhi oleh berbagai faktor termasuk didalamnya adalah motivasi responden.

Jadi dengan melihat hasil penelitian ini diharapkan kepada perawat agar selalu menjamin keselamatan pasien dan mencegah terjadinya infeksi rumah sakit atau infeksi nosokomial dengan melakukan cuci tangan yang baik dan benar berdasarkan five moment hand hygiene. Kegagalan dalam melakukan kebersihan tangan adalah merupakan penyebab utama terjadinya infeksi rumah sakit dan akanmengakibatkan penyebaran mikroorganisme multiresisten di fasilitas pelayanan kesehatan (Boyce dan Pittet, 2001). Menjaga kebersihan tangan adalah metode yag paling mudah, murah dan efektif dilakukan untuk mencegah infeksi rumah sakit (Susiati, 2008). Melalui program-program untuk peningkatan pengetahuan dan motivasi perawat maka diharapkan pelaksanaan budaya kebersihan tangan akan menjadi semakin baik. 
Program rumah sakit yang bersifat meningkatkan pengetahuan dan motivasi perawat guna meningkatkan kepatuhan cuci tangan/budaya kebersihan tangan perlu direncanakan dengan seksama dan diimplementasikan dan dilaksanakan secara berkesinambungan. Sosialisasi secara langsung maupun melalui media (leaflet), bimbingan dan pengawasanlangsung oleh atasan serta pemberian reward dan punishment akan efektif mengatasi permasalahan tersebut. Selain itu perlu adanya role model yang dapat dijadikan sebagai panutan oleh perawat, juga diyakini akan mampu meningkatkan kepatuhan perawat dalam melakukan kebersihan tangan. Sehingga potensi terjadinya peningkatan kejadian infeksi rumah sakit khususnya di RSU Surya Husadha Denpasar dapat dicegah atau dikurangi.

\section{SIMPULAN}

Berdasarkan hasil penelitian dan pembahasan diketahui bahwa terdapat hubungan umur, pendidikan, pengetahuan, dan motivasi dengan kepatuhan mencuci tangan di RSU Surya Husada, oleh sebab itu agar edukasi, bimbingan dan pengawasan kepada perawat tentang pelaksanaan cuci tangan terus ditingkatkan agar kepatuhan cuci tangan semakin baik sehingga kejadian infeksi rumah sakit dapat dicegah.

\section{DAFTAR PUSTAKA}

Boyce \& Pittet D. 2002. Cost Implications Of Successful Hand Hygiene Promotion. Infect Control Hosp Epidemiology

Hasibuan, M.S.P. 2005. Manajemen Sumber Daya Manusia, Edisi Revisi. Bumi Aksara: Jakarta
Natalina, 2010. Hubungan Karakteristik Perawat dengan Tingkat Kepatuhan Perawat Melakukan Cuci Tangan di Rumah Sakit Columbia Asia Medan (Skripsi ) Universitas Darma Agung Medan

Notoadmojo. 2005. Statistik Untuk Penelitian, Jakarta, Pt Rineka Cipta Schaffer. 2005. Situasi Infeksi Nosokomial Di Beberapa Negara Masa lampau dan Kini: Majalah Kesehatan Masyarakat Indonesia tahun XXII

Setiawati, 2015 Analisis Faktor-faktor yang Mempengaruhi Ketaatan Petugas Kesehatan Melakukan Hand Hygiene Dalam Mencegah Infeksi Nosokomial Di Ruang Perinatologi RSUPN Dr Cipto Mangunkusumo, Jakarta (Skripsi) Universitas Indonesia

Sumaningrum, 2015. Faktor Yang Berhubungan Dengan Kepatuhan Perawat Mencuci Tangan Handrub Pada Saat Pemasangan Infus di Rumah Sakit X Di Jawa Timur (Skripsi) Universitas Airlangga Surabaya

Tohamik. 2003. Nosocomial Infections In Adult Intensive Care Units, The Lancet, Volume 42 